\title{
Modern Dynamics of High-Mountain Forests in the Northern Urals: Major Trends
}

\author{
Nadezhda M. Devi*a, \\ Vladimir V. Kukarskiha, Arina A. Galimova ${ }^{b}$, \\ Maksim O. Bubnov a and Sergey V. Zykov ${ }^{\mathrm{a}}$ \\ ${ }^{a}$ Institute of Plant and Animal Ecology UB RAS \\ 202, 8 Marta Str., Ekaterinburg, 620144, Russia \\ ${ }^{b}$ Ural State Forest Engineering University \\ 37 Sibirsky trakt, Ekaterinburg, 620100, Russia
}

Received 06.04.2018, received in revised form 10.06.2018, accepted 14.07.2018

\begin{abstract}
In many regions climate warming has caused shifts of the upper and polar boundaries of woody vegetation and changes in the structure and composition of tree stands. Regions whose vegetation has not experienced large-scale anthropogenic impacts have attracted particular interest of researchers assessing the natural dynamics of stands. This work is devoted to the study of the age and morphological structure of the tree layer of mixed woodlands and forests on the Eastern spur of the Molebny Kamen' ridge (Northern Urals). The study is based on the quadrat sampling method and tree-ring analysis. The tree-line ecotone shows significant changes in the composition and morphological and age structure of forest stands that have occurred in this region since the mid-twentieth century, with the rising summer temperatures and increasing winter precipitation. Climatic response analysis, contained in 4 generalized tree-ring chronologies constructed for the Siberian larch, Siberian pine, Siberian fir and Siberian spruce, suggests that radial growth of the trees is mostly influenced by spring and early summer growing conditions. The results of the study can be used in forestry and forest management activities.
\end{abstract}

Keywords: stand structure, stand dynamics, upper tree-line, radial growth, Siberian larch, Siberian spruce, Siberian pine, Siberian fir, Downy birch, Northern Urals.

Citation: Devi N.M., Kukarskih V.V., Galimova A.A., Bubnov M.O., Zykov S.V. Modern dynamics of high-mountain forests in the Northern Urals: major trends. J. Sib. Fed. Univ. Biol., 2018, 11(3), 248-259. DOI: 10.17516/1997-1389-0069.

(C) Siberian Federal University. All rights reserved

This work is licensed under a Creative Commons Attribution-NonCommercial 4.0 International License (CC BY-NC 4.0).

* Corresponding author E-mail address: nadya@ipae.uran.ru 


\title{
Современная динамика высокогорных лесов
} на Северном Урале: основные тенденции

\author{
Н.М. Дэви ${ }^{\mathrm{a}}$, В.В. Кукарских ${ }^{\mathrm{a}}$, \\ А.А. Галимова ${ }^{\sigma}$, М.О. Бубнов ${ }^{\text {a }}$, С.В. Зыков ${ }^{\text {a }}$ \\ ${ }^{a}$ Институт экологии растений и животных УрО РАН \\ Россия, 620144, Екатеринбург, ул. 8 Марта, 202 \\ ${ }^{6}$ Уральский государственный лесотехнический университет \\ Россия, 620100, Екатеринбург, Сибирский тракт, 37
}

На фоне наблюдаемого потепления климата во многих регионах отмечается смещение верхней и полярной границ распространения древесной растительности, изменение структуры и состава древостоев. Особый интерес вызывают регионы, растительность которых не испытывала масштабных антропогенных воздействий, что позволяет оценить естественную динамику древостоев. Данная работа посвящена изучению возрастной и морфологической структуры древесного яруса смешанных редколесий и лесов на восточном отроге хребта Молебный Камень (Северный Урал). В основу исследования положень методы пробных площуадей и древесно-кольцевого анализа. В экотоне верхней границы древесной растительности отмечены существенные изменения состава, морфологической и возрастной структуры древостоев, произошедшие на фоне повышения летних температур и увеличения количества зимних осадков, наблюдаемых в данном районе со второй половины ХХ в. Анализ климатического отклика, содержащуегося в четырех обобщенных древесно-кольцевых хронологиях, построенных по лиственнице сибирской, сосне сибирской, пихте сибирской и ели сибирской, показал, что на радиальный прирост изученных деревьев наибольшее влияние оказывают весенние и раннелетние условия произрастания. Полученные данные могут быть использованы при проведении лесохозяйственных и лесоустроительных работ.

Ключевые слова: структура древостоев, динамика древостоев, экотон верхней границьь древесной растительности, радиальный прирост, лиственница сибирская, ель сибирская, сосна сибирская, пихта сибирская, береза пушистая, Северный Урал.

\section{Введение}

В последние десятилетия наблюдается устойчивый и продолжающийся рост температуры воздуха во многих регионах Земли, что подтверждается инструментальными и спутниковыми наблюдениями и является предметом исследований многих научных групп и программ (IPCC, 2016).

Изменение общей климатической обстановки и отдельных параметров климата влия- ет на функционирование экосистем, в частности приводит к изменению видового состава, пространственного размещения и радиального прироста деревьев, произрастающих на верхнем пределе своего распространения (Толмачев, 1962; Шмитхюзен, 1966; Kearney, 1982; Kullman, 1986; Taylor, 1995; Briffa et al., 2002; Kharuk et al., 2017). Интенсификация процессов лесовозобновления, подъем верхней границы леса, увеличение сомкнутости 
древостоев в XX в. отмечается во многих горных провинциях Урала (Moiseev et al., 2004; Shiyatov et al., 2005; Мazepa, 2005; Моисеев и др., 2008; Devi et al., 2008; Grigor'ev et al., 2013; Hagedorn et al., 2014; Shiyatov and Mazepa, 2015). Цель представленной работы - оценить состав, морфологическую и возрастную структуру древостоев на верхнем пределе распространения древесной растительности на хребте Молебный Камень (Северный Урал) и установить основные факторы, влияющие на появление, распространение и радиальный прирост деревьев.

\section{Район исследований}

Сбор материала для определения временных интервалов жизни деревьев и факторов, влияющих на появление и рост деревьев, осуществлялся на восточном отроге хребта Молебный Камень (рис. 1). Климат в районе исследования умеренно-континентальный с продолжительной зимой (до 6 месяцев) и коротким прохладным летом. По данным гидрометеостанции «Мойва» $\left(61^{\circ} 12^{\prime}\right.$ с.ш., $59^{\circ} 08^{\prime}$ в.д.), средняя годовая температура воздуха в горно-лесном поясе составляет минус $2{ }^{\circ} \mathrm{C}$, общее количество осадков за год 1300-1600 мм. Преобладающие ветры имеют западное направление. Средняя продолжительность залегания снега составляет 210230 дней, средняя высота снежного покрова в лесу равна 110 см (Семенов и др., 2009).

\section{Материалы и методы}

Описание морфометрических параметров деревьев и сбор дендрохронологических образцов были произведены на 9 пробных тест-полигонах общей площадью 0,18 га, заложенных вдоль высотного градиента на северо-восточном склоне отрога Масипальнелпаттуил $\left(61^{\circ} 16^{\prime}\right.$ с.ш., 59²0' в.д.) между высотами 760 и 860 м над ур. м.

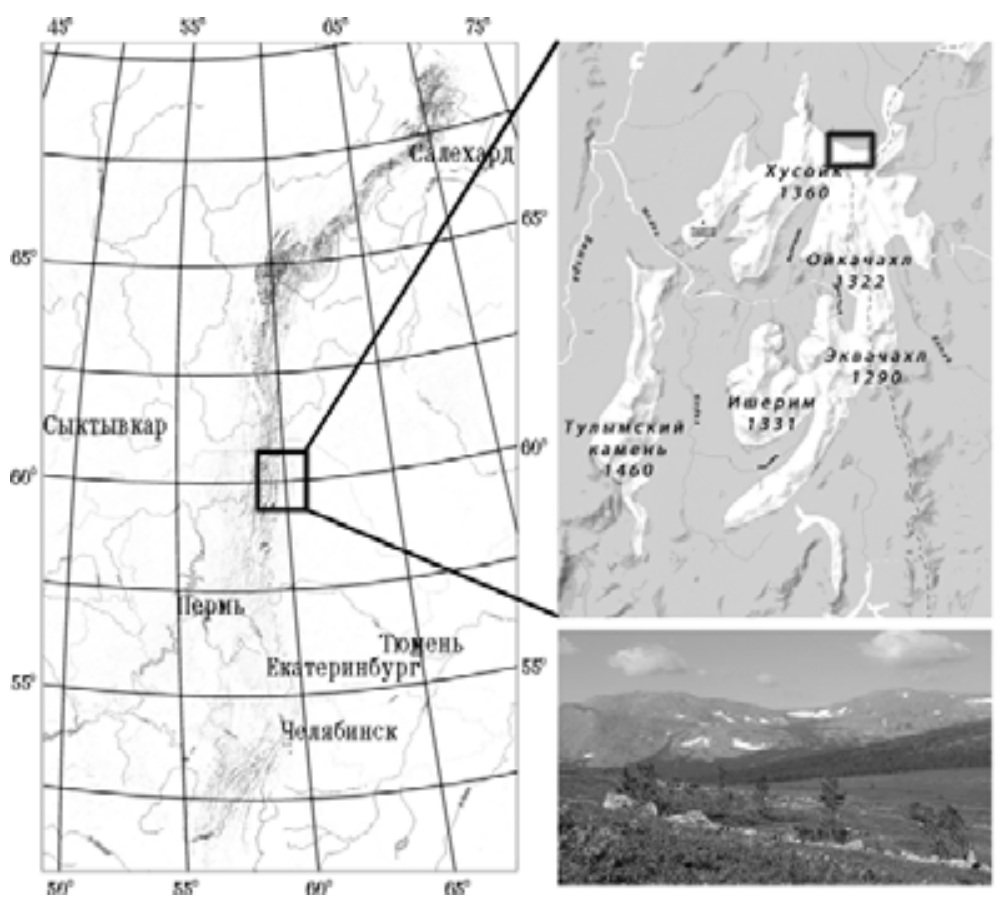

Рис. 1. Общий вид и карта - схема района исследования

Fig. 1 . The general view and schematic map of the study area 
На пробных площадях был произведен полный перечет деревьев и подроста с учетом высоты и диаметров ствола у основания и на высоте 1,3 м каждой особи. Всего учтено и описано 472 дерева и элемента подроста. С каждого взят керн или поперечный спил для определения возраста.

Измерение ширины годичных колец и перекрестная датировка индивидуальных серий прироста осуществлены согласно общепринятым методикам (Шиятов и др., 2000). Качество датировки статистически проверено в программе COFECHA (Holmes, 1983). Индексирование индивидуальных древеснокольцевых хронологий проведено в программном пакете ARSTAN методом кубического сплайна (Cook and Kairiukstis, 1990). Обобщенные древесно-кольцевые хронологии получены усреднением индивидуальных серий. Расчет отклика радиального прироста на климатические переменные проводился с помощью расчета функций отклика бутстреп методом в программе DENDROCLIM2002 (Biondi and Waikul, 2004).

В результате было получено 4 обобщенных стандартизированных ряда прироста, для построения которых использовано 79 наиболее старых деревьев (15 для лиственницы сибирской, 20 для ели сибирской, 14 для сосны сибирской и 30 для пихты сибирской).

Сравнение среднемесячных значений климатических переменных проводили с помощью непараметрического критерия МаннаУитни в программе Statistica.

\section{Результаты и обсуждение}

Состав и морфологическая структура древостоев

На изученных площадках отмечается существенное изменение состава, структуры, густоты и возраста древостоев по мере увеличения высоты над ур. м. (табл. 1).
В сомкнутом лесе и редколесьях в составе древостоя преобладает береза пушистая, имеющая многоствольную форму роста (57 и $75 \%$ от общего количества деревьев). Доля участия лиственницы в составе древостоя гораздо ниже (27 и $16 \%$ ), хотя она имеет более высокие значения по среднему диаметру и высоте, чем береза.

Вклад ели в состав древостоя на всех высотных уровнях является незначительным и составляет 5-7 \%. На обследованные пробные площади не попала пихта сибирская, но стоит отметить ее присутствие (на уровне 5-10 \%) в составе древостоя на нижнем высотном уровне.

В верхней части профиля береза пушистая и лиственница сибирская полностью исчезают из состава древостоев, а доминирующим видом становится сосна сибирская, имеющая кустовидную форму роста. Также отмечаются единичные особи ели сибирской, произрастающие в виде ковровидной формы и стланика (рис. 2). Это связано с тем, что на данных участках деревья подвержены экстремальной ветровой нагрузке, а малая мощность снегового покрова приводит к промерзанию почвы и снежной абразии деревьев, превышающих высоту снега.

На всех изученных площадках отмечается большое количество всходов и подроста сосны сибирской, количество которого при переходе от нижнего к верхнему уровню увеличивается в 25 раз. Почти полное отсутствие проростков и подроста лиственницы сибирской и ели сибирской на всех высотных уровнях говорит о дальнейшем уменьшении доли участия указанных пород в древостое. Учеты подроста березы пушистой в средней и нижней частях профиля показали, что доля ее участия в составе изученных древостоев сохранится в дальнейшем на уровне $50 \%$. 
Таблица 1. Характеристика древостоев на различных высотных уровнях хр. Молебный Камень Table 1. Characterization of tree stands at different altitudes on the Molebny Kamen' ridge

\begin{tabular}{|c|c|c|c|c|}
\hline Вид & Pinus sibirica & Picea obovata & Larix sibirica & Betula pubescens \\
\hline \multicolumn{5}{|c|}{ Тундра с одиночными деревьями (860 м над ур. м) } \\
\hline Диаметр, см & $1,5 \pm 0,1$ & $4,5 \pm 0,7$ & - & - \\
\hline Высота, см & $31 \pm 2$ & $73 \pm 9$ & - & - \\
\hline \multirow{2}{*}{ Возраст, лет (mean/max) } & $19 \pm 2$ & $59 \pm 12$ & \multirow[b]{2}{*}{ - } & \multirow{2}{*}{-} \\
\hline & 105 & 115 & & \\
\hline \multirow{2}{*}{$\begin{array}{l}\text { Густота древостоя, шт/га } \\
\text { (деревья/подрост) }\end{array}$} & 71 & 61 & \multirow{2}{*}{-} & \multirow{2}{*}{-} \\
\hline & 2635 & 0 & & \\
\hline \multicolumn{5}{|c|}{ Редколесье (810 м над ур. м.) } \\
\hline Диаметр, см & $1,1 \pm 0,1$ & $7,4 \pm 3,1$ & $27,9 \pm 6,4$ & $8,3 \pm 0,9$ \\
\hline Высота, см & $37 \pm 3$ & $270 \pm 110$ & $720 \pm 90$ & $310 \pm 30$ \\
\hline \multirow{2}{*}{ Возраст, лет (mean/max) } & $12 \pm 1$ & $50 \pm 9$ & $55 \pm 10$ & $55 \pm 5$ \\
\hline & 21 & 70 & 105 & 158 \\
\hline \multirow{2}{*}{$\begin{array}{l}\text { Густота древостоя, шт/га } \\
\text { (деревья/подрост) }\end{array}$} & 19 & 59 & 136 & 642 \\
\hline & 954 & 19 & 0 & 428 \\
\hline \multicolumn{5}{|c|}{ Верхняя граница сомкнутых лесов (760 м над ур. м.) } \\
\hline Диаметр, см & $15,9 \pm 7,1$ & $13,5 \pm 1,1$ & $21,7 \pm 4,4$ & $11,3 \pm 1,7$ \\
\hline Высота, см & $395 \pm 165$ & $515 \pm 15$ & $640 \pm 70$ & $460 \pm 50$ \\
\hline \multirow{2}{*}{ Возраст, лет (mean/max) } & $48 \pm 14$ & $49 \pm 12$ & $94 \pm 18$ & $114 \pm 17$ \\
\hline & 107 & 61 & 217 & 228 \\
\hline \multirow{2}{*}{$\begin{array}{l}\text { Густота древостоя, шт/га } \\
\text { (деревья/подрост) }\end{array}$} & 140 & 70 & 350 & 734 \\
\hline & 105 & 0 & 0 & 140 \\
\hline
\end{tabular}
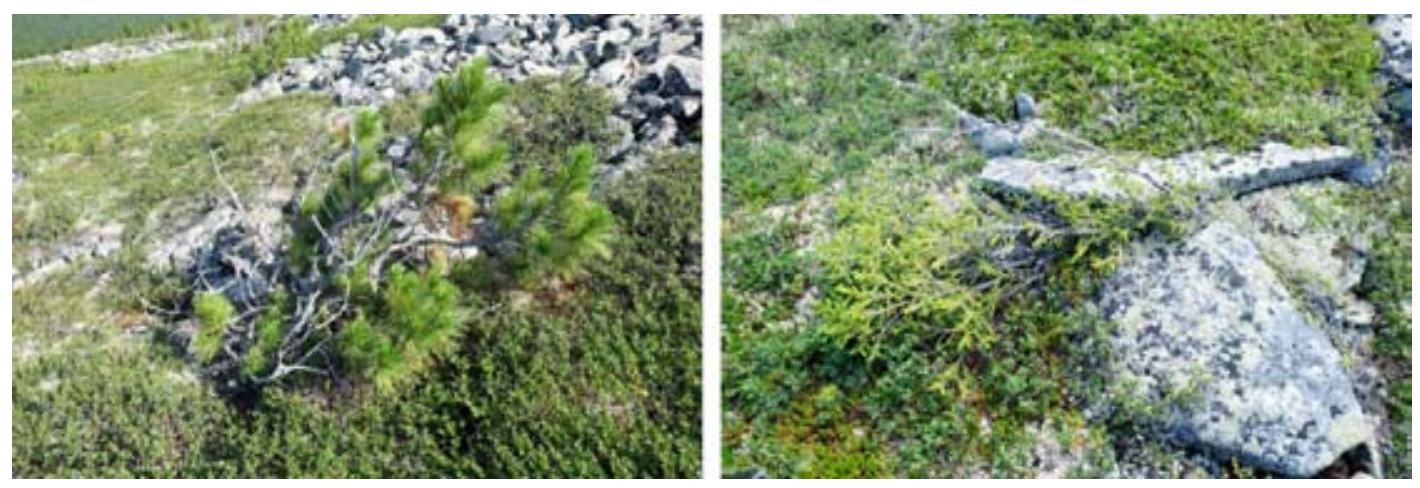

Рис. 2. Кустовидная форма роста Pinus sibirica (слева) и стланик Picea obovata (справа)

Fig. 2. Shrub form of Pinus sibirica (left) and creeping form of Picea obovata (right)

\section{Возрастная структура древостоев}

Анализ возрастной структуры и динамики плотности древостоев (рис. 3), выполненный на основе абсолютного датирования дендрохронологических образ- цов, показал, что в нижней части профиля время жизни наиболее старых растущих деревьев составляет 215-230 лет, но их число не превышает 2 \% от общего количества деревьев. 

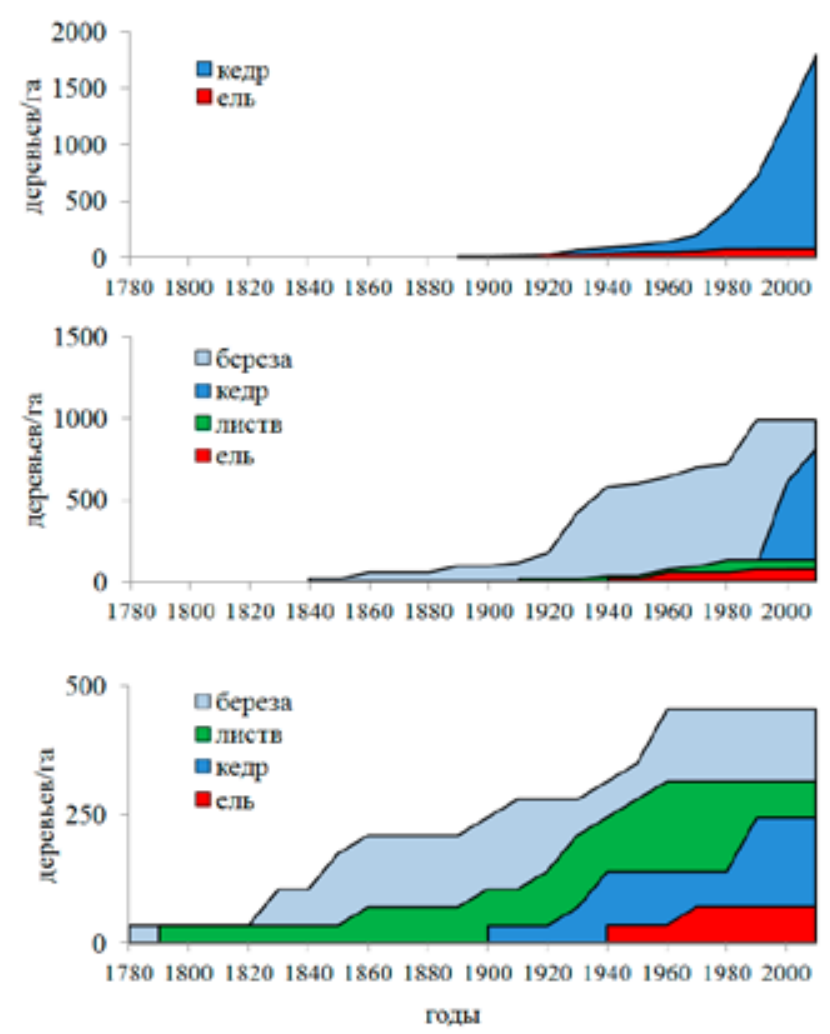

Рис. 3. Динамика плотности деревьев в экотоне верхней границы древесной растительности (верхний, средний и нижний уровни соответственно) на хр. Молебный Камень, Северный Урал

Fig. 3. Dynamics of tree density in the tree-line ecotone (upper, middle and lower levels, respectively) on the Molebny Kamen' ridge, Northern Ural

В течение XIX в. происходило заселение данной территории многоствольными деревьями березы и лиственницы. До середины $\mathrm{XX}$ в. густота древостоев увеличивалась в основном за счет появления новых вертикальных стволов у многоствольных деревьев. В 1930-1970-е гг. наблюдалось массовое появление деревьев всех видов одноствольной формы роста.

В средней части профиля формирование древостоев происходило в течение XX в. Максимум возобновления приходится на 19401950-е гг. за счет массового появления многоствольных деревьев березы и одноствольных деревьев лиственницы и ели. В последние 20 лет на данной территории началось активное возобновление кедра.
В верхней части профиля формирование древостоев началось в 1980-е гг. и продолжается до настоящего времени.

Наблюдаемая динамика структуры древостоев происходит на фоне значимых изменений основных климатических параметров в пределах района исследований. С 1976 по 2015 г. наблюдается значимое увеличение среднемесячных температур марта, мая-июня и октября по сравнению с периодом 19361975 гг. в среднем на $1,33{ }^{\circ} \mathrm{C}$ (рис. $4 A$ ). Также заметно увеличение количества осадков января, апреля, августа и октября в среднем на 13,8 мм (рис. 45$)$.

Наибольшие изменения произошли в характере снежного покрова. При сравнении данных по максимальной высоте снеж- 

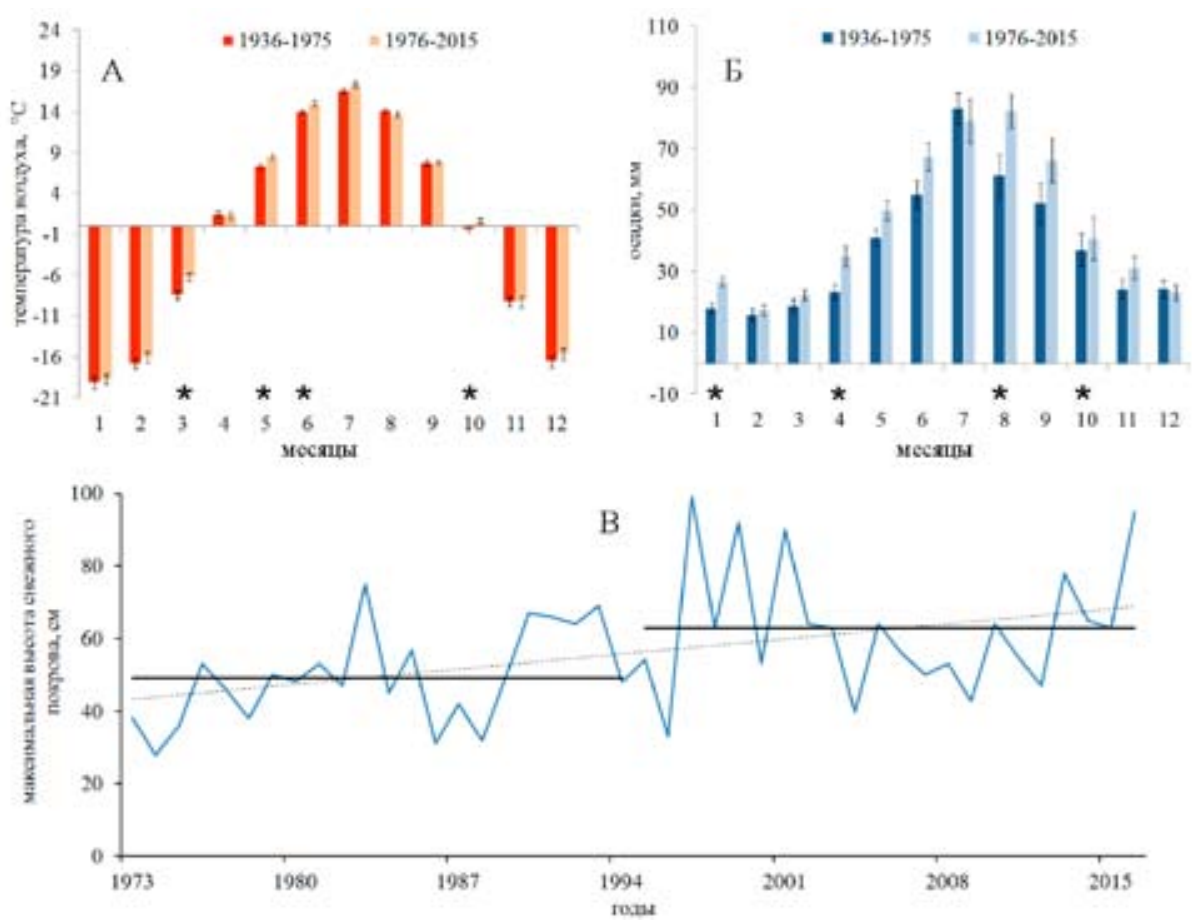

Рис. 4. Средние многолетние значения температур воздуха (А) и осадков (Б) за периоды 1936-1975 и 1976-2015 гг. (значения, достоверно отличающиеся при $\mathrm{p}<0,05, \mathrm{~N}=39$ отмечены звездочкой), а также многолетняя динамика максимальной высоты снежного покрова (В), по данным м/с «Ивдель», жирными линиями отмечены средние многолетние уровни снега за периоды 1973-1994 и 1995-2016 гг., пунктирная линия - линейный тренд высоты снежного покрова

Fig. 4. Average long-term values of air temperatures (A) and precipitation (B) for the periods from 1936 to 1975 and from 1976 to 2015 (values significantly different at $\mathrm{p}<0.05, \mathrm{~N}=39$, are marked with an asterisk) and long-term dynamics of the maximum height of the snow cover (B) according to the data from the Ivdel' weather station; bold lines denote average long-term values for 1973-1994 and 1995-2016, dotted line is the snow cover linear trend

ного покрова установлено, что за последние 22 года (с 1995 по 2016) наблюдалось достоверное увеличение высоты снега на 138 мм по сравнению с периодом 1973-1994 гг. или почти на $25 \%$ (рис. $4 B$ ).

\section{Радиальный прирост деревьев}

Анализ радиального прироста деревьев показал, что средняя ширина годичных колец у различных видов, произрастающих на верхней границе сомкнутых лесов, составляет 1,01 -1,44 мм, наблюдаемые межвидовые различия статистически не значимы (табл. 2). При переходе от сомкнутого леса к редколесью радиальный прирост деревьев закономерно и значимо уменьшается. В условиях разреженных древостоев (в средней и верхней частях профиля) статистически значимые различия в ширине радиального прироста деревьев между высотами отсутствуют.

\section{Дендроклиматический анализ}

В результате стандартизации индивидуальных хронологий построено четыре обобщенных стандартизированных ряда по ширине радиального прироста хвойных деревьев сем. Pinaceae, произрастающих в лесном поясе на хр. Молебный Камень (рис. 5). Основные характеристики обобщенных хронологий представлены в табл. 3. 
Таблица 2. Изменчивость радиального прироста древесных растений (среднее $\pm \mathrm{SE}$ ) на разных высотных уровнях

Table 2. Variability of radial growth of trees (mean $\pm \mathrm{SE}$ ) at different altitudes

\begin{tabular}{|l|c|c|c|c|}
\hline \multirow{2}{*}{\multicolumn{1}{|c|}{ Тип древостоя }} & \multicolumn{4}{|c|}{ Радиальный прирост, мм } \\
\cline { 2 - 5 } & P. sibirica & P. obovata & L. sibirica & B. pubescens \\
\hline Тундра с одиночными деревьями & $0,49 \pm 0,04$ & $0,39 \pm 0,06$ & - & - \\
\hline Редколесье & $0,47 \pm 0,03$ & $0,36 \pm 0,10$ & $0,80 \pm 0,09$ & $0,72 \pm 0,05$ \\
\hline Верхняя граница сомкнутых лесов & $1,12 \pm 0,44$ & $1,44 \pm 0,24$ & $1,04 \pm 0,14$ & $1,01 \pm 0,06$ \\
\hline
\end{tabular}

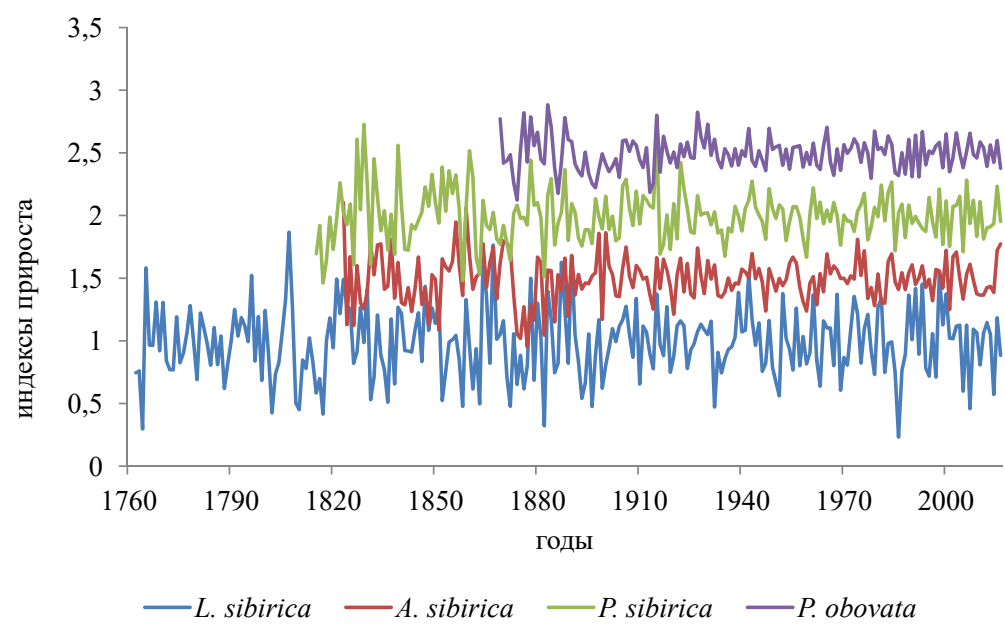

Рис 5. Обобщенные древесно-кольцевые хронологии по ширине радиального прироста лиственницы сибирской, пихты сибирской, сосны сибирской и ели сибирской, произрастающих в лесном поясе на хр. Молебный Камень

Fig 5. Generalized tree-ring chronologies for the tree-ring width of the Siberian larch, Siberian fir, Siberian pine and Siberian spruce growing in the forest belt on the Molebny Kamen' ridge

Таблица 3. Характеристики обобщенных древесно-кольцевых хронологий

Table 3. Characterization of generalized tree-ring chronologies

\begin{tabular}{|l|c|c|c|}
\hline \multicolumn{1}{|c|}{ Вид } & Длительность, лет & Чувствительность & EPS $>0,85$ \\
\hline Larix sibirica & 255 & 0,34 & 1790 \\
\hline Abies sibirica & 194 & 0,21 & 1910 \\
\hline Pinus sibirica & 202 & 0,24 & 1850 \\
\hline Picea obovata & 148 & 0,16 & 1920 \\
\hline
\end{tabular}

Bce обобщенные древесно-кольцевые хронологии проявляют высокую синхронность и значимо коррелируют между собой (рис. 5, табл. 4). Высокая синхронность между рядами указывает на то, что определяющую роль в динамике прироста изучаемых видов играют климатические факторы. Достаточно слабовыраженная корреляция и частичная 
Таблица 4. Коэффициенты корреляции между рядами прироста различных видов хвойных деревьев $(\mathrm{N}=145, \mathrm{p}<0,05)$

Table 4. Coefficients of correlation between the growth series of various coniferous trees $(\mathrm{N}=145, \mathrm{p}<0.05)$

\begin{tabular}{|c|c|c|c|}
\hline \multirow{2}{*}{ Хронология } & \multicolumn{3}{|c|}{ Хронология } \\
\cline { 2 - 4 } & A. sibirica & P. sibirica & P. obovata \\
\hline L. sibirica & 0,29 & 0,44 & 0,36 \\
\hline A. sibirica & & 0,34 & 0,27 \\
\hline P. sibirica & & & 0,40 \\
\hline
\end{tabular}
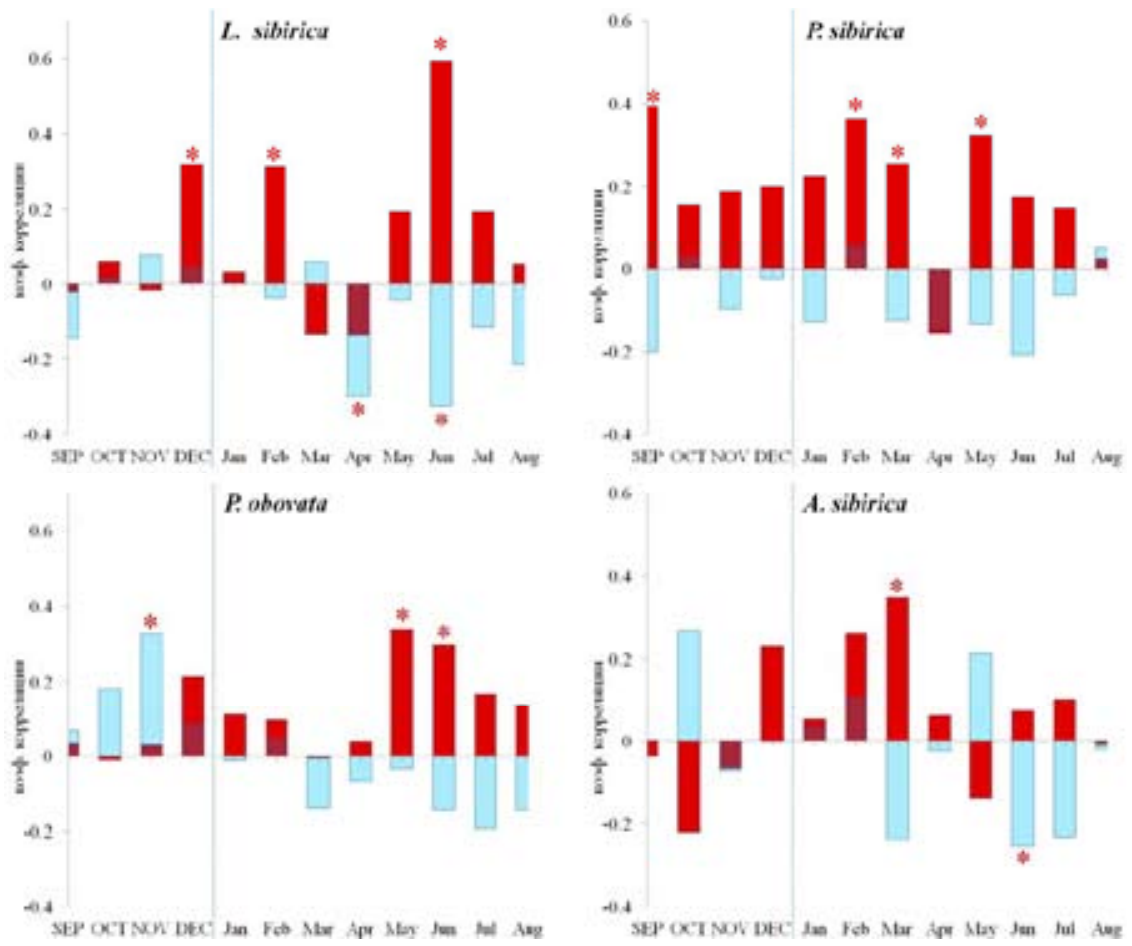

Рис. 6. Функции отклика годичного прироста основных лесообразующих пород на температуру воздуха (красным) и количество осадков (синим) с сентября предшествующего по август текущего года, по данным м/с «Ивдель». * - коэффициенты значимы при $\mathrm{p}<0,05, \mathrm{~N}=48$

Fig. 6. Functions of the annual growth response of the main forest-forming species to air temperature (red) and precipitation (blue) from September of the previous year to August of the current year according to the data from the Ivdel' weather station. ${ }^{*}$ - coefficients are significant at $\mathrm{p}<0.05, \mathrm{~N}=48$

асинхронность между погодичными и многолетними колебаниями в рядах прироста говорят о том, что прирост деревьев разных видов лимитируется отличными друг от друга климатическими факторами.

Полученные обобщенные хронологии были сопоставлены с основными кли- матическими переменными - средними месячными температурами воздуха и количеством осадков (рис. 6). В качестве климатических предикторов использовался ряд инструментальных метеонаблюдений по метеостанции «Ивдель» с 1966 по 2016 г. как ближайшей к району исследований 
(6068' с.ш., 6043' в.д.) и не имеющей пропусков в рядах данных.

Анализ климатического отклика показал, что влияние климатических факторов на ширину радиального прироста у разных пород значительно различается. Вечнозеленые породы - кедр, ель и пихта - проявляют связь со среднемесячными температурами воздуха месяцев, предшествующих началу вегетации (март-май). У пихты и лиственницы значимым фактором, влияющим на прирост, является избыточное увлажнение в начале вегетации (отрицательная связь с осадками июня). У ели и лиственницы - температурный фон июня. Полученные данные говорят о большей степени влияния весенних и ранне-летних условий произрастания на радиальный прирост изученных деревьев, так как в это время происходит интенсификация ростовых процессов после периода покоя.

\section{Заключение}

На фоне повышения средних летних температур воздуха и увеличения количества зимних осадков, наблюдаемого на $\mathrm{Ce}$ верном Урале в течение ХХ в., произошло значительное изменение видового состава и увеличение густоты древостоев в экотоне верхней границы древесной растительности.

В начале XX в. в составе древостоев доминировали лиственница сибирская и береза пушистая. Со второй половины ХХ в. происходит резкое увеличение доли ели сибирской и экспансия указанных видов в современные редколесья. В конце ХХ в. в составе древостоев на всех высотных уровнях появляется подрост сосны сибирской, которая на текущий момент формирует верхнюю границу леса. Почти полное отсутствие проростков и подроста лиственницы сибирской и ели сибирской на всех высотных уровнях говорит о дальнейшем уменьшении доли участия указанных пород в древостое.

Отклик радиального прироста хвойных, произрастающих в горно-лесном поясе, видоспецифичен, на радиальный прирост изученных деревьев наибольшее влияние оказывают весенние и раннелетние условия произрастания. Среди всех рассмотренных видов наилучшие возможности для реконструкции термического режима имеет лиственница сибирская.

Работа выполнена при финансовой поддержке проектов РФФИ № 15-04-063874 и 1634-01144.

\section{Список литературы}

Моисеев П.А., Бартыш А.А., Горяева А.В., Кошкина Н.Б., Нагимов З.Я., Галако В.А. (2008) Динамика подгольцовых древостоев на склонах Серебрянского Камня (Северный Урал) в последние столетия. Хвойные бореальной зоны, 25(1-2): 21-28 [Moiseev P.A., Bartish A.A., Goryaeva A.V., Koshkina N.B., Nagimov Z.Y., Galako V.A. (2008) Dynamics of subalpine stands on slopes of Serebryansky kamen' (North Urals) in the last centuries. Conifers of the Boreal Area, 25(1-2): 21-28 (in Russian)]

Семенов В.В., Акимов В.А., Белковская Т.П., Ильиных С.И., Колбин В.А., Мухутдинов О.И., Паньков Н.Н. (2009) Вишера заповедная. Соликамск, Гос. природ. заповедник «Вишерский», 64 c. [Semenov V.V., Akimov V.A., Belkovskaya T.P., Ilyin S.I., Kolbin V.A., Mukhutdinov O.I., Pan'kov N.N. (2009) Vishera reserve. Solikamsk, Vishera nature reserve, 64 p. (in Russian)]

$$
-257-
$$


Толмачев А.И. (1962) Основы учения об ареалах (введение в хорологию растений). Л., Издательство ЛГУ, 99 с. [Tolmachev A.I. (1962) Basic principles of the geographic ranges (an introduction to the plant chorology). Leningrad, Leningrad State University, 99 p. (in Russian)]

Шиятов С.Г., Ваганов Е.А., Кирдянов А.В., Круглов В.Б., Мазепа В.С., Наурзбаев М.М., Хантемиров Р.М. (2000) Методы дендрохронологии. Часть I. Основы дендрохронологии. Сбор и получение древесно-кольцевой информации. Красноярск, КрасГУ, 80 с. [Shiyatov S.G., Vaganov E.A., Kirdyanov A.V., Kruglov V.B., Mazepa V.S., Naurzbaev M.M., Hantemirov R.M. (2000) Methods of dendrochronology. Part I. The Basics of Dendrochronology. Collecting and obtaining tree-ring information. Textbook. Krasnoyarsk, Krasnoyarsk State University, 80 p. (in Russian)]

Шмитхюзен И. (1966) Общая география растительности. М., Прогресс, 310 с. [Schmithusen I. (1966) The general geography of vegetation. Moscow, Progress, 310 p. (in Russian)]

Biondi F., Waikul K. (2004) DENDROCLIM2002: a C++ program for statistical calibration of climate signals in tree-ring chronologies. Computers \& Geosciences, 30(3): 303-311

Briffa K.R., Osborn T.J., Schweingruber F.H., Jones P.D., Shiyatov S.G., Vaganov E.A., (2002) Tree-ring width and density data around the Northern Hemisphere: Part 2, spatio-temporal variability and associated climate patterns. The Holocene, 12(6): 759-789

Cook E.R., Kairiukstis L.A. (Eds.) (1990) Methods of dendrochronology. Springer Netherlands, Dordrecht

Devi N., Hagedorn F., Moiseev P., Bugmann H., Shiyatov S., Mazepa V., Rigling A. (2008) Expanding forests and changing growth forms of Siberian larch at the Polar Urals treeline during the $20^{\text {th }}$ century. Global Change Biology, 14(7): 1581-1591

Grigor'ev A.A., Moiseev P.A., Nagimov Z.Y. (2013) Dynamics of the timberline in high mountain areas of the nether-polar Urals under the influence of current climate change. Russian Journal of Ecology, 44(4): 312-323

Hagedorn F., Shiyatov S.G., Mazepa V.S., Devi N.M., Grigor'ev A.A., Bartysh A.A., Fomin V.V., Kapralov D.S., Terent'ev M., Bugman H., Rigling A., Moiseev P.A. (2014) Treeline advances along the Urals mountain range - driven by improved winter conditions? Global Change Biology, 20(11): $3530-3543$

Holmes R.L. (1983) Computer-assisted quality control in tree-ring dating and measurement. TreeRing Bulletin, 43: 69-78

IPCC (2016) Climate Change 2014: Synthesis Report. Contribution of Working Groups I, II and III to the Fifth Assessment Report of the Intergovernmental Panel on Climate Change. Core Writing Team, R.K.P. and L.A.M. (Eds.) IPCC, Geneva, Switzerland, 151 p.

Kearney M.S. (1982) Recent seedling establishment at timberline in Jasper National Park, Alta. Canadian Journal of Botany, 60(11): 2283-2287

Kharuk V.I., Im S.T., Dvinskaya M.L., Ranson K.J., Petrov I.A. (2017) Tree wave migration across an elevation gradient in the Altai Mountains, Siberia. Journal of Mountain Science, 14(3): 442-452

Kullman L. (1986) Recent tree-limit history of Piceaabies in the southern Swedish Scandes. Canadian Journal of Forest Research, 16(4): 761-771

Mazepa V.S. (2005) Stand density in the last millennium at the upper tree-line ecotone in the Polar Ural Mountains. Canadian Journal of Forest Research, 35(9): 2082-2091 
Moiseev P.A., van der Meer M., Rigling A., Shevchenko I.G. (2004) Effect of climatic changes on the formation of Siberian spruce generations in subglotsy tree stands of the Southern Urals. Russian Journal of Ecology, 35(3): 135-143

Shiyatov S.G., Mazepa V.S. (2015) Contemporary expansion of Siberian larch into the mountain tundra of the Polar Urals. Russian Journal of Ecology, 46(6): 495-502

Shiyatov S.G., Terent'ev M.M., Fomin V.V. (2005) Spatiotemporal dynamics of forest-tundra communities in the polar urals. Russian Journal of Ecology, 36(2): 69-75

Taylor A.H. (1995) Forest expansion and climate change in the mountain hemlock (Tsuga mertensiana) zone, Lassen Volcanic National Park, California, U.S.A. Arctic \& Alpine Research, 27(3): 207-216 